\title{
Acute Pancreatitis: First and Sole Manifestation of Small Cell Carcinoma of Lung
}

\author{
Muhammad Ali Khan ${ }^{\mathrm{a}, \mathrm{e}}$, Faraz Khan Luni ${ }^{\mathrm{a}}$, Sehrish Kamal ${ }^{\mathrm{a}}$, Yaseen Alastal ${ }^{\mathrm{a}}$, Abdullah Alwardia ${ }^{\mathrm{a}}$, \\ Jacob Bieszczad ${ }^{b}$, Luis De Las Casas ${ }^{c}$, Youngsook Yoon ${ }^{\mathrm{d}}$
}

\begin{abstract}
Small cell carcinoma of the lung is an aggressive disease that tends to metastasize early in its course and has a poor prognosis. Pancreatic metastasis generally constitutes a late manifestation of this disease and most patients do not have organ specific symptoms (jaundice, abdominal pain and weight loss), and it is incidentally discovered on imaging studies. However, acute pancreatitis as the initial presentation of small cell carcinoma of lung is extremely rare. We came across a 71-year-old female who was admitted to the hospital for abdominal pain secondary to acute pancreatitis. Further workup revealed metastatic small cell carcinoma of lung. In English literature we found 11 other cases of small cell carcinoma of lung which had acute pancreatitis as their sole presentation. Therefore, it should be kept in mind as a very rare cause of acute pancreatitis in the right setting.
\end{abstract}

Keywords: Acute pancreatitis; Small cell carcinoma of lung; Metastasis-induced pancreatitis; Liver metastases

\section{Introduction}

Small cell carcinoma of the lung is an aggressive disease that tends to metastasize early in its course and has a poor prognosis. Pancreatic metastasis generally constitutes a late manifestation of this disease and most patients do not have organ specific symptoms (jaundice, abdominal pain and weight loss), and it is incidentally discovered on imaging studies. Acute pancreatitis as the initial presentation of small cell carcinoma of the lung is a rare entity and during English literature review

Manuscript accepted for publication July 29, 2014

anternal Medicine, University of Toledo, Toledo, OH, USA

${ }^{b}$ Radiology, University of Toledo, Toledo, OH, USA

'Pathology, University of Toledo, Toledo, OH, USA

dPulmonary and Critical Care, University of Toledo, Toledo, OH, USA

'Corresponding Author: Muhammad Ali Khan, Internal Medicine, University of Toledo, 3000 Arlington Avenue, Toledo, OH 43614, USA. Email:Muhammad.khan2@utoledo.edu

doi: http://dx.doi.org/10.14740/jmc1896w we identified only 11 reported cases of small cell carcinoma of the lung with acute pancreatitis as the presenting diagnosis. In this report, we present an interesting case of small cell carcinoma of lung, which had acute pancreatitis as the initial manifestation of the disease.

\section{Case Report}

A 71-year-old female with significant history of tobacco abuse presented with complaints of epigastric abdominal pain radiating to the back for 2 days. She also reported weight loss of 40 lbs during the past 4 months. There was no history of alcohol abuse or gall stones. Physical examination was unremarkable except for epigastric tenderness and scleral icterus. Laboratory investigation revealed amylase 1,469 U/L, lipase 1,632 U/L, total bilirubin $3.9 \mathrm{mg} / \mathrm{dL}$, alkaline phosphatase $332 \mathrm{IU} / \mathrm{L}$, ALT $79 \mathrm{IU} / \mathrm{L}$ and AST $88 \mathrm{IU} / \mathrm{L}$ and $\mathrm{Ca} 8.6 \mathrm{mg} / \mathrm{dL}$. Ultrasound gallbladder did not reveal any gall stones. CT scan of the abdomen showed diffuse enlargement of pancreas.

Diagnosed with acute pancreatitis, she had MRCP which showed multiple hyper intense hepatic nodules (Fig. 1) on background of iron deposition and mild dilation of biliary system. ERCP revealed displaced major papilla, distal common bile duct indentation which was suspicious for distal bile duct stricture. Shelving was also noted with poor drainage of the contrast for which a plastic biliary stent was placed. Brushing from the common bile duct showed atypical ductal proliferation. Tumor markers revealed CA19-9 624 U/mL, CEA 62.8 $\mathrm{ng} / \mathrm{mL}$ and AFP $1 \mathrm{U} / \mathrm{mL}$.

$\mathrm{CT}$ of the chest revealed $2.5 \mathrm{~cm}$ irregular mass in the superior hilar aspect of the right lower lobe of lung with irregular margins (Fig. 2). A CT-guided biopsy of the liver lesions showed malignant cells with immunostaining positive for TTF-1, chromogranin and synaptophysin; Ki67 revealed nuclear reactivity for about $95 \%$ of tumor cells. Flow cytometric studies demonstrated that the tumor cells expressed CD56 (neuroendocrine marker) but were negative for lymphohemotopoietic markers.

All these findings were compatible with a diagnosis of metastatic small cell carcinoma of lung.

Our patient declined further investigation and treatment. She was referred for palliative care and passed away within 10 days. Permission for autopsy was not granted. 


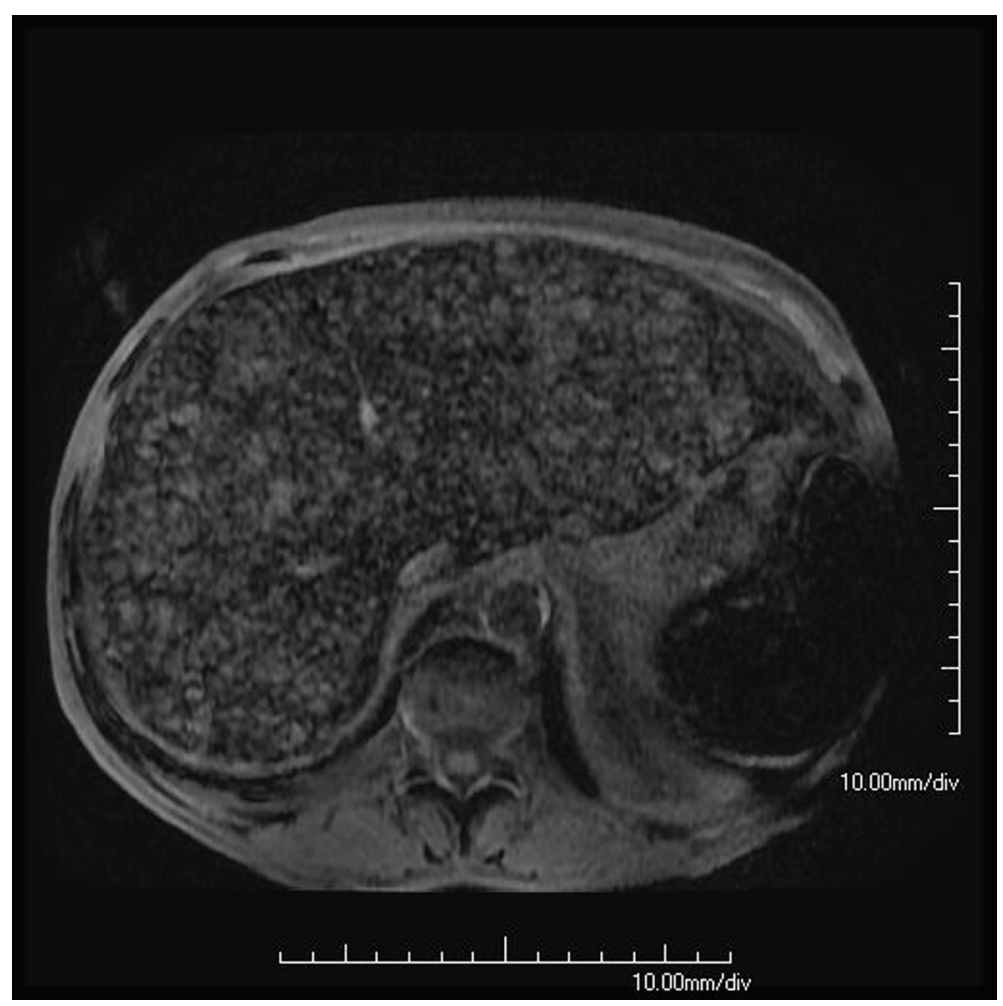

Figure 1. T1-weighted image showing enlarged liver with innumerable nodules.

\section{Discussion}

Pancreatic metastasis has ranged from $1.6 \%$ to $5.9 \%$ in different autopsy studies [1]. A lot of different cancers have been reported to cause pancreatic metastases; these include lung cancers (small cell carcinoma and non-small cell carcinoma), renal cell carcinoma, breast carcinoma, colon cancer and prostate cancer. Renal cell carcinoma appeared to be the most predominant tumor causing pancreatic metastasis which was fol- lowed by lung carcinoma [2].

In 1973 Levine et al first described the occurrence of acute pancreatitis in a patient during the progression of small cell carcinoma of the lung [3]. Acute pancreatitis is seldom associated with lung cancer, and in such instances it is usually a late manifestation of the disease. Several reports have identified this occurrence during the advancement of lung cancer. However, acute pancreatitis being the sole presentation of small cell carcinoma of the lung is an exceptional event. In English lit-

Table 1. Acute Pancreatitis as Initial Manifestation of Small Cell Carcinoma of Lung

\begin{tabular}{llll}
\hline Case & Age & Gender & Chest radiography \\
\hline Schmitt et al [4] & 58 & Male & Left hilar lymphadenopathy \& left upper lobe infiltrate \\
Chowhan et al [5] & 55 & Female & Left upper lobe collapse \& mediastinal mass \\
Stewart et al [6] & 44 & Male & Left lower lobe consolidation \\
Hall et al [7] & 67 & Male & Left upper lobe and mediastinal mass \\
Noseda et al [8] & 58 & Male & Lingula collapse \\
Evans et al [9] & 45 & Female & Mediastinal mass \\
Maclennan et al [10] & 56 & Female & Mediastinal mass \\
Huang et al [11] & 68 & Female & Left lower lobe mass \\
Tanaka et al [12] & 51 & Female & Left para-hilar mass \\
Hussain et al [13] & 53 & Female & Mediastinal mass \\
Leung et al [14] & 83 & Female & Bilateral lung nodules \\
Our case & 71 & Female & Right lower lobe mass \\
\hline
\end{tabular}




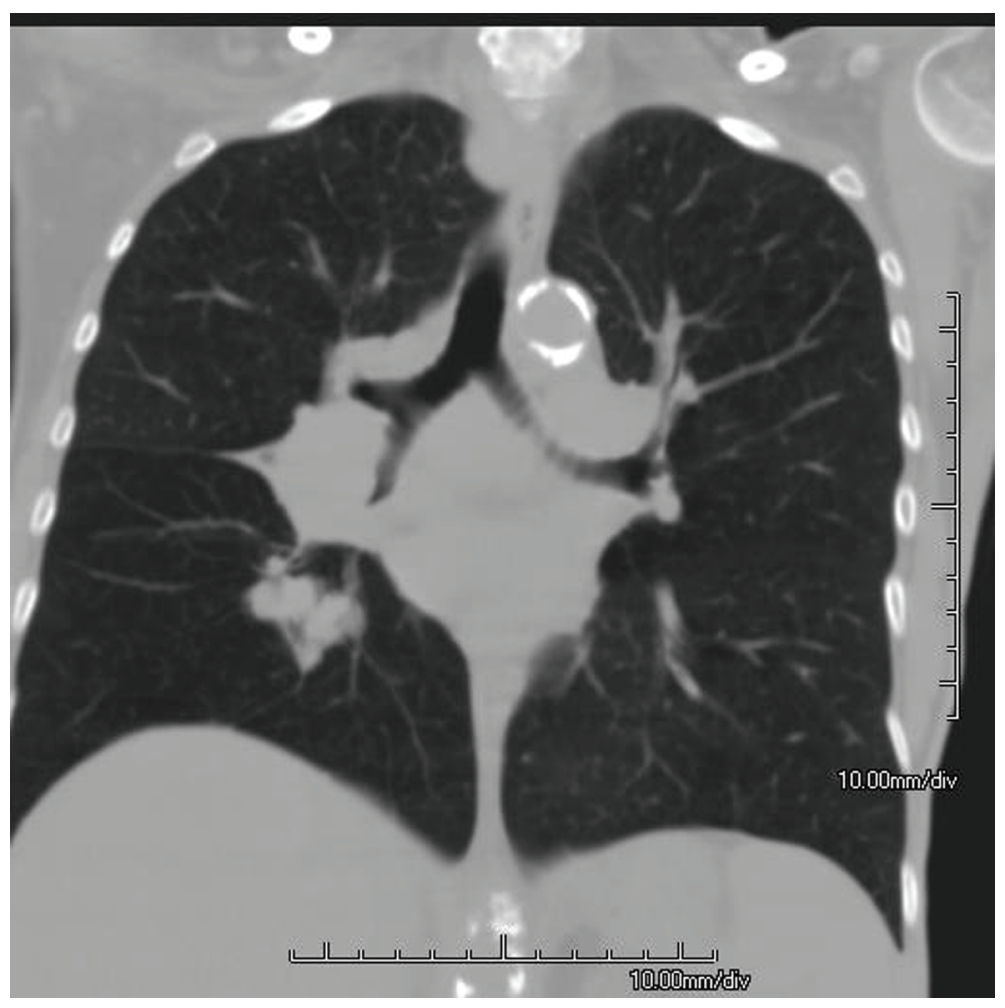

Figure 2. Irregular mass-like density in the superior hilar aspect of right lower lobe. Mediastinal lymph nodes present.

erature we found 11 other cases of small cell carcinoma clinically presenting with acute pancreatitis for the first time (Table 1) [4-14]. Interestingly, we found involvement of left lung in $57 \%$ cases and a female predominance $64 \%$ in all these cases. Age of patients was found to be (mean \pm SD) $59 \pm 11.33$ years.

Several mechanisms have been postulated to describe metastasis-induced pancreatitis. First is obstruction of pancreatic duct by metastases or peri-pancreatic compression due to enlargement of regional lymph nodes. This can cause activation of pancreatic enzymes which lead to autolysis. Second possible mechanism can be vascular compromise caused by invasion of metastatic neoplastic cells [15]. Some case reports have deemed hypercalcemia as a causative mechanism for acute pancreatitis in patients of small cell carcinoma of the lungs [13]. On the contrary, some small cell lung cancer patients with acute pancreatitis had no evidence of pancreatic metastasis on autopsy (no other usual cause of pancreatitis was identified) making it a possible paraneoplastic syndrome [16].

Being a rare scenario reported as low as $0.12 \%$ in one case series [6], no standard treatment regimens of chemotherapy have been devised for metastasis-induced acute pancreatitis in small cell carcinoma of lung. Although our patient did not pursue chemotherapy, the prognosis is generally poor in these patients, being described as a median survival of 12 days without chemotherapy after the onset of pancreatitis. Liu et al reported a survival advantage of the group that received chemotherapy compared to those who did not (162 days vs. 25 days, $\mathrm{P}<0.01)$ [17]. Tanaka et al [12] also reported a better mean survival duration of 3.9 months with chemotherapy in such patients as compared to 22 days with supportive care. We believe more series and studies are required to formulate a standard approach for the management of such patients.

\section{Acknowledgement}

This abstract will be presented in American College of Physicians, Ohio Meeting on October 17, 2014 at Columbus, OH, USA.

\section{Conflict of Interest}

All authors have no conflict of interest.

\section{Disclosure}

All authors have no financial disclosures.

\section{References}

1. Adsay NV, Andea A, Basturk O, Kilinc N, Nassar H, Cheng JD. Secondary tumors of the pancreas: an analysis of a surgical and autopsy database and review of the literature. Virchows Arch. 2004;444(6):527-535.

2. Minni F, Casadei R, Perenze B, Greco VM, Marrano N, Margiotta A, Marrano D. Pancreatic metastases: observa- 
tions of three cases and review of the literature. Pancreatology. 2004;4(6):509-520.

3. Levine M, Danovitch SH. Metastatic carcinoma to the pancreas. Another cause for acute pancreatitis. Am J Gastroenterol. 1973;60(3):290-294.

4. Schmitt JK. Pancreatitis and diabetes mellitus with metastatic pulmonary oat-cell carcinoma. Ann Intern Med. 1985;103(4):638-639.

5. Chowhan NM, Madajewicz S. Management of metastases-induced acute pancreatitis in small cell carcinoma of the lung. Cancer. 1990;65(6):1445-1448.

6. Stewart KC, Dickout WJ, Urschel JD. Metastasis-induced acute pancreatitis as the initial manifestation of bronchogenic carcinoma. Chest. 1993;104(1):98-100.

7. Hall M, Bundred NJ, Hall AW. Oat cell carcinoma of the bronchus and acute pancreatitis. Eur J Surg Oncol. 1987;13(4):371-372.

8. Noseda A, Gangji D, Cremer M. Acute pancreatitis as presenting symptom and sole manifestation of small cell lung carcinoma. Dig Dis Sci. 1987;32(3):327-331.

9. Evans AT. Necrotising pancreatitis and diabetes associated with disseminated small cell carcinoma of lung. Scott Med J. 1988;33(6):377.

10. Maclennan AC, Macleod IA. Case report: small cell carcinoma induced acute pancreatitis. $\mathrm{Br} \mathrm{J}$ Radiol. 1993;66(782):161-162.
11. Huang YW, Yang JC, Chang YL, Tsang YM, Wang TH. Acute pancreatitis combined with acute Budd-Chiari syndrome as the initial manifestation of small cell lung cancer. J Formos Med Assoc. 2005;104(6):431-435.

12. Tanaka H, Nakazawa T, Yoshida M, Miyabe K, Okumura F, Naitoh I, Hayashi K, et al. Metastasis-induced acute pancreatitis in a patient with small cell carcinoma of the lungs. JOP. 2009;10(5):557-561.

13. Hussain A, Adnan A, El-Hasani S. Small cell carcinoma of the lung presented as acute pancreatitis. Case report and review of the literature. JOP. 2012;13(6):702-704.

14. Leung E, Prasher A, Francombe J, Brocklebank A, Joy H. Metastasis-induced pancreatitis: case report. Prague Med Rep. 2013;114(1):39-42.

15. Muranaka T, Teshima K, Honda H, Nanjo T, Hanada K, Oshiumi Y. Computed tomography and histologic appearance of pancreatic metastases from distant sources. Acta Radiol. 1989;30(6):615-619.

16. Allan SG, Bundred N, Eremin O, Leonard RC. Acute pancreatitis in association with small cell lung carcinoma: potential pitfall in diagnosis and management. Postgrad Med J. 1985;61(717):643-644.

17. Liu SF, Zhang S, Chen YC, Fang WF, Lin MC, Su MC, Wang CC. Experience of cancer care for metastasisinduced acute pancreatitis patients with lung cancer. J Thorac Oncol. 2009;4(10):1231-1235. 